Research Article

\title{
Investigation of Phonon Vibrational Modes in Ga, Al, Fe, Co, Ni, and Zn Doped (110)-Oriented PBCO Thin Films
}

\author{
Hom Kandel $\left(\mathbb{D},{ }^{1}\right.$ Milko Iliev, ${ }^{2}$ Nathan Arndt, ${ }^{1}$ and Tar-Pin Chen ${ }^{3}{ }^{3}$ \\ ${ }^{1}$ Department of Physics, University of Wisconsin-Parkside, Kenosha, WI 53144, USA \\ ${ }^{2}$ Texas Center for Superconductivity, University of Houston, Houston, TX 77204, USA \\ ${ }^{3}$ Department of Physics and Astronomy, University of Arkansas, Little Rock, AR 72204, USA
}

Correspondence should be addressed to Hom Kandel; kandel@uwp.edu

Received 9 March 2020; Accepted 9 June 2020; Published 28 June 2020

Academic Editor: Alicia E. Ares

Copyright ( $\odot 2020$ Hom Kandel et al. This is an open access article distributed under the Creative Commons Attribution License, which permits unrestricted use, distribution, and reproduction in any medium, provided the original work is properly cited.

We performed Raman scattering measurements and a comprehensive study of different types of Raman modes associated with phonon vibrations on pure and $\mathrm{Ga}, \mathrm{Al}, \mathrm{Fe}, \mathrm{Co}, \mathrm{Ni}$, and $\mathrm{Zn}$ doped (110)-oriented $\mathrm{PrBa}_{2} \mathrm{Cu}_{3} \mathrm{O}_{7}$ (PBCO) thin films to identify the substitution of $\mathrm{Cu}(1)$ or $\mathrm{Cu}(2)$ ions in PBCO lattice. In Raman spectrum of (110)-oriented PBCO thin film, we observed four prominent $A_{\mathrm{g}}$ type Raman modes at $\sim 130 \mathrm{~cm}^{-1}, \sim 150 \mathrm{~cm}^{-1}, \sim 440 \mathrm{~cm}^{-1}$, and $\sim 520 \mathrm{~cm}^{-1}$ corresponding to Ba, $\mathrm{Cu}(2), \mathrm{O}(2)-\mathrm{O}(3)$ in-phase, and $\mathrm{O}(4)$ apical oxygen vibration along $c$-axis, respectively. The Raman mode of pure PBCO at $\sim 520 \mathrm{~cm}^{-1}$ softened on $\mathrm{Ga}, \mathrm{Al}, \mathrm{Fe}$, and $\mathrm{Co}$ doped PBCO thin films while it remained unaffected on $\mathrm{Zn}$ and Ni doped PBCO thin films. We explain these results in the context of their correlation with $\mathrm{Cu}(1)-\mathrm{O}(4)$ and $\mathrm{Cu}(2)-\mathrm{O}(4)$ bond lengths. In addition, we observed a new Raman mode near $610 \mathrm{~cm}^{-1}$ in the Raman spectra of $\mathrm{Ga}, \mathrm{Al}, \mathrm{Fe}$, and Co doped PBCO thin films, an infrared (IR) active mode that became Raman active when the symmetry was broken at the $\mathrm{Cu}-\mathrm{O}$ chain site after the partial substitution of $\mathrm{Cu}(1)$ ion. Moreover, the "O (2)-O (3) in-phase Raman mode" near $440 \mathrm{~cm}^{-1}$ remained unaffected in $\mathrm{Fe}, \mathrm{Co}, \mathrm{Ga}$, and Al doped PBCO thin films but softened in $\mathrm{Zn}$ and Ni doped PBCO thin films. Based on these results, we argue that $\mathrm{Ga}, \mathrm{Al}, \mathrm{Fe}$, and Co ions replace $\mathrm{Cu}(1)$ ion at the $\mathrm{Cu}-\mathrm{O}$ chain site, break the crystal symmetry, and produce disorder locally, whereas $\mathrm{Zn}$ and $\mathrm{Ni}$ ions replace $\mathrm{Cu}(2)$ ion at the $\mathrm{CuO}_{2}$ plane of the PBCO lattice structure.

\section{Introduction}

Raman spectroscopy is an ideal analytical tool for site detection of $\mathrm{Cu}$ ion substitution in the family of cuprate oxide compound $\mathrm{RBa}_{2} \mathrm{Cu}_{3} \mathrm{O}_{7}(\mathrm{R}=$ Rare Earth element). Two of the most useful members of this family are high critical temperature $\left(T_{\mathrm{c}}\right)$ superconductor $\mathrm{YBa}_{2} \mathrm{Cu}_{3} \mathrm{O}_{7-\delta}(\mathrm{YBCO})$ and cuprate oxide insulator $\mathrm{PrBa}_{2} \mathrm{Cu}_{3} \mathrm{O}_{7-\delta}(\mathrm{PBCO})$, which share similar lattice structure and oxygen chemistry [1] and are used in wide range of superconducting electronic and magnetic devices. The substitution of $\operatorname{Pr}$ for $\mathrm{Y}$ in $\mathrm{Y}_{1-\mathrm{x}} \operatorname{Pr}_{\mathrm{x}} \mathrm{Ba}_{2}$ $\mathrm{Cu}_{3} \mathrm{O}_{7-\delta}$ suppresses $T_{\mathrm{c}}$ with superconductivity disappearing for $x>=0.50$ [2]. Substitutions of $\mathrm{Cu}$ ions in $\mathrm{PBCO}$ by trivalent metal ions such as $\mathrm{Fe}, \mathrm{Co}, \mathrm{Ga}$, and $\mathrm{Al}$ and divalent metal ions such as $\mathrm{Ni}$ and $\mathrm{Zn}$ are of special interest in applied superconductivity and materials science as these elements have preferential role in the substitution of $\mathrm{Cu}$ ions, i.e., from the $\mathrm{Cu}-\mathrm{O}$ chains or $\mathrm{CuO}_{2}$ planes of PBCO lattice. Raman spectroscopy is one of the many tools to detect the $\mathrm{Cu}$ ion sites of the substituted trivalent or divalent ions.

As shown in Figure 1, the unit cell of PBCO is either tetragonal or orthorhombic, which contains two dimpled $\mathrm{Cu}$ (2)-O (2)-O (3) planes $\left(\mathrm{CuO}_{2}\right.$ planes), separated by a single Pr atom that form a two-dimensional rectangular network. The $\mathrm{O}(1)$ atoms along the $b$-axis direction $(y$-axis in Figure 1) form the $\mathrm{Cu}(1)-\mathrm{O}$ (1) chains at the top or bottom of the each unit cell. There are no equivalent oxygen atoms along $a$-axis direction ( $x$-axis direction in Figure 1 ) and hence no $\mathrm{Cu}(1)-\mathrm{O}(1)$ chain in this direction. O (4) oxygen forms a bridge between the $\mathrm{Cu}(1)$ and $\mathrm{Cu}(2)$ ions. X-ray and neutron diffraction measurements performed on the metaldoped PBCO powder samples, namely, $\operatorname{PrBa}_{2}\left[\mathrm{Cu}_{1-\mathrm{x}} \mathrm{M}_{\mathrm{x}}\right]_{3} \mathrm{O}_{7}$ 


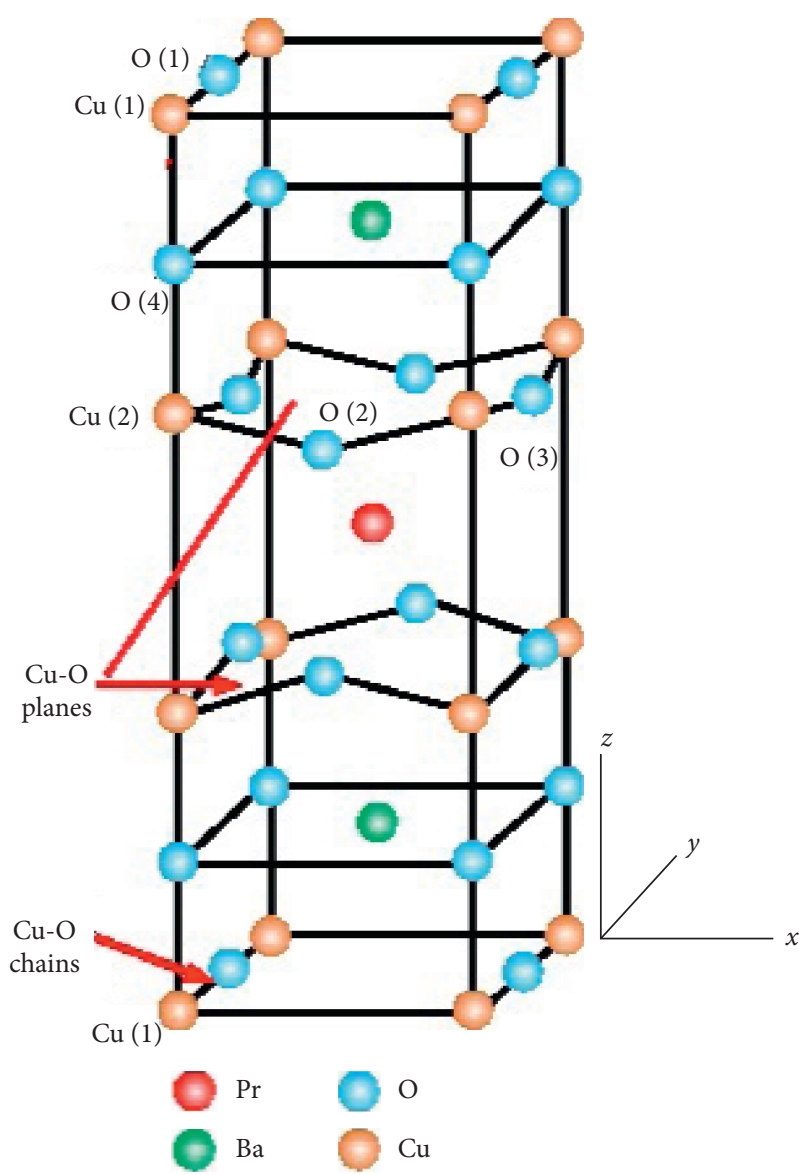

Figure 1: A unit cell of $\mathrm{PrBa}_{2} \mathrm{Cu}_{3} \mathrm{O}_{7-\delta}$.

$(\mathrm{M}=\mathrm{Al}, \mathrm{Co}, \mathrm{Fe}, \mathrm{Ga}, \mathrm{Ni}$, and $\mathrm{Zn}$ and $x=0.00,0.05,0.10,0.15$, and 0.20 by our research group showed that the crystalline structure of PBCMOs are of orthorhombic $\left(P_{m m m}\right.$ space group), same as those for PBCO and YBCO. However, the orthorhombicity of PBCMO was found to be small than that of PBCO. X-ray data indicated no significant second phases for substituting $\mathrm{Cu}$ by $\mathrm{Al}, \mathrm{Co}, \mathrm{Fe}$, and $\mathrm{Ga}$ up to $20 \%$.

Raman tensor corresponding to a crystal are described by different point groups as described in [3] and Table 1, which show a tensor representation for orthorhombic and tetragonal space groups. Most RBCO compounds fall into one of these two groups and, a vibrational mode is allowed if the element of the Raman tensor, called the Raman active mode is nonzero. On the contrary, if the element in the Raman tensor is zero, the mode is Raman forbidden, is inactive, and will not show in the Raman spectrum. Vibrational mode of $A_{g}$ symmetry are observed in the orthorhombic $\left(\mathrm{D}_{2 \mathrm{~h}}\right)$ point group for a parallel polarization of incident and scattered light, for example, $x(z, z) x^{\prime}$. However, Raman active modes $\mathrm{B}_{1 \mathrm{~g}}, \mathrm{~B}_{2 \mathrm{~g}}, \mathrm{~B}_{3 \mathrm{~g}}$, and $\mathrm{E}_{\mathrm{g}}$ are observed with crossed polarizations, for example, $y(x, z) y^{\prime}$. Raman scattering from the $A_{g}$ symmetry mode in $D_{2 h}$ point group is allowed only in $x x, y y$, or $z z$ polarization symmetries and the Raman scattering from $\mathrm{B}_{1 \mathrm{~g}}, \mathrm{~B}_{2 \mathrm{~g}}$, and $\mathrm{B}_{3 \mathrm{~g}}$ symmetries are allowed only for $(x y$ or $y x),(x z$ or $z x)$, and $(y z$ or $z y)$ polarization geometries, respectively.
TABle 1: Raman Tensor in $\mathrm{D}_{2 \mathrm{~h}}$ (orthorhombic) and $\mathrm{D}_{4 \mathrm{~h}}$ (tetragonal) point group [3].

$$
\begin{aligned}
& \text { Orthorhombic structure } \\
& \begin{array}{llll}
\text { Ag } & \mathrm{B}_{1 \mathrm{~g}} & \mathrm{~B}_{2 \mathrm{~g}} & \mathrm{~B}_{3}
\end{array} \\
& \left(\begin{array}{ccc}
x x & & \\
& y y & \\
& & z z
\end{array}\right)\left(\begin{array}{c}
y^{x y} \\
\end{array}\right.
\end{aligned}
$$

Tetragonal structure

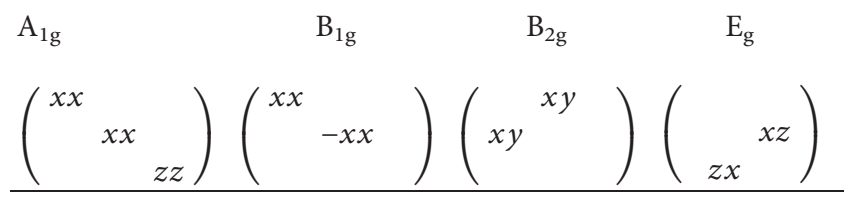

Most $\mathrm{RBa}_{2} \mathrm{Cu}_{3} \mathrm{O}_{7-\delta}$ compounds are centro-symmetric crystals and have inversion centers [3,4]. For example, in YBCO and PBCO, the sites of the $\mathrm{Y}$ or Pr atom, $\mathrm{Cu}$ (1) atom, and the $\mathrm{O}(1)$ atom in the $\mathrm{Cu}-\mathrm{O}$ chains behave as inversion centers. The vibration of both atoms in the $\mathrm{Cu}-\mathrm{O}$ chain move in the same direction and it is called an odd vibration. Raman spectroscopy involves two odd photons, whose combination is even and couples only to even vibrations. On the contrary, infrared (IR) spectroscopy involves only one photon (odd in dipole approximation) and therefore couples only to odd vibrations. The vibrations of the $\mathrm{Cu}(1)$ and $\mathrm{O}(1)$ atoms are thus Raman inactive and IR-active. The remaining atoms do not have centers of inversion in the unit cell. They appear as pairs of equivalent atoms connected by the inversion and can give rise to either odd (both atoms moving in the same direction.) or even (motion in opposite directions) vibrations.

The atoms of Figure 1 can vibrate along the $z$ as well as along the $x$ and $y$ directions. Even vibrations along $z$-axis appear to be much stronger in the Raman spectra than their $x-y$ counterparts are. If $\mathrm{O}(1)$ atoms of the chains are removed, the unit cell of Figure 1 becomes tetragonal $\left(D_{4 h}\right.$ point group).

For the structure of Figure 1, five $z$-polarized Raman phonon vibration mode exist [4]: vibrations of $\mathrm{Ba}$ $\left(115 \mathrm{~cm}^{-1}\right), \mathrm{Cu}(2)\left(150 \mathrm{~cm}^{-1}\right), \mathrm{O}(2)-\mathrm{O}$ (3) plane oxygens $\left(340 \mathrm{~cm}^{-1}, 440 \mathrm{~cm}^{-1}\right)$, and the apical oxygen $\mathrm{O}$ (4) $\left(500-520 \mathrm{~cm}^{-1}\right)$. The vibrations of the oxygen atoms lie in the $300 \mathrm{~cm}^{-1}-700 \mathrm{~cm}^{-1}$ ranges. The Raman vibration mode at $500 \mathrm{~cm}^{-1}$ in $\mathrm{YBCO}$ and $520 \mathrm{~cm}^{-1}$ in PBCO is due to axial vibration of the apical oxygen atom between the two copper atoms: $\mathrm{Cu}(1)$ and $\mathrm{Cu}(2)$. It is an $\mathrm{A}_{\mathrm{g}}$ mode and has a ccpolarization, which refers to incident radiation polarized along the $c$-axis of the crystal and scattered radiation polarized along the $c$-axis. The $440 \mathrm{~cm}^{-1}$ peak is also an $\mathrm{A}_{\mathrm{g}}$ mode. It is assigned to $\mathrm{O}(2)-\mathrm{O}(3)$ in phase binding motion, consistent with cc-polarization.

Theoretically, there are five phonons of $\mathrm{A}_{\mathrm{g}}$ symmetry in the orthorhombic phase of $\mathrm{PBCO}$ and four $\mathrm{A}_{1 \mathrm{~g}}$ and one $\mathrm{B}_{1 \mathrm{~g}}$ phonons in the tetragonal phase of $\mathrm{PBCO}$. When the PBCO structure becomes tetragonal, four of the five $A_{g}$ phonons become $A_{1 g}$ and the remaining $A_{g}$ phonon becomes $B_{1 g}$ or $B_{1 g}$-like. The difference between $A_{g}, A_{1 g}$, and $B_{1 g}$ is in their 
Raman tensors and therefore in their polarization selection rules. We expect no intensity for the $\mathrm{B}_{1 \mathrm{~g}}$ or $\mathrm{B}_{1 \mathrm{~g}}$-like mode in the $z z$ polarization spectra.

Detailed analysis of the Raman scattering of YBCO have been published by various researchers such as Thomsen and Kaczmarczyk [3], Cardona [4], McCarty et al. [5], Pinczuk and Burstein [6], Hemley and Mao [7], Thomsen and Cardona [8], Kakihana et al. [9], Roughani [10], and Bates et al. $[11,12]$. Raman scattering studies also on PBCO and metal-doped $\mathrm{PBCO}$ have been reported in references [13-15]. In this paper, we present a comprehensive study of Raman scattering on pure and $\mathrm{Ga}, \mathrm{Al}, \mathrm{Fe}, \mathrm{Co}, \mathrm{Ni}$, and $\mathrm{Zn}$ doped (110)-oriented $\mathrm{PrBa}_{2} \mathrm{Cu}_{3} \mathrm{O}_{7}$ (PBCO) thin films in which $20 \% \mathrm{Cu}$ atoms in $\mathrm{Cu}(1)$ or $\mathrm{Cu}(2)$ sites are substituted by $\mathrm{Fe}, \mathrm{Co}, \mathrm{Ni}, \mathrm{Zn}, \mathrm{Ga}$, and $\mathrm{Al}$.

\section{Materials and Methods}

(110)-oriented $\operatorname{PrBa}_{2}\left(\mathrm{Cu}_{1-\mathrm{x}} \mathrm{M}_{\mathrm{x}}\right)_{3} \mathrm{O}_{7}(x=0,0.2$ and $\mathrm{M}=\mathrm{Fe}$, $\mathrm{Co}, \mathrm{Ni}, \mathrm{Zn}, \mathrm{Ga}$, and $\mathrm{Al}$ ) thin films were grown by pulsed laser deposition technique (PLD) as described in [16, 17]. The (110) epitaxy of the films was confirmed using X-ray diffraction.

Raman scattering measurements were performed on these thin films using Horiba Jobin Yvon T64000 Triple Raman spectrometer equipped with a liquid nitrogen cooled charge-coupled device (CCD) and a microscope in conjunction with computer-controlled $X Y Z$ stage and an optical cryostat Microstat (Oxford instruments). The $488 \mathrm{~nm}$ and $633 \mathrm{~nm}$ lines of lasers were used for the excitation at a power of $0.21 \mathrm{~mW}$ under the $\times 100$ objective. The spectra were taken with parallel scattering configurations $[(001),(001)]=z z$ or $[110,110]=x^{\prime} x^{\prime}$ which means that both incident and scattered light polarizations were parallel to either the $(z z)$ or $\left(x^{\prime} x^{\prime}\right)$ dimension of the substrate.

For the description of the scattering configurations, we followed the convention of Porto notation $a(b c) d[18]$, where the first and fourth letters denote, respectively, the directions of incident and scattered light in a Cartesian $x y z$ system with the axes along the crystallographic directions. The second and third letters give the polarization of the incident and scattered light, respectively. Our spectra were taken with parallel scattering configurations $[(001),(001)]=$ $z z$ or $[(110,110)]=x^{\prime} x^{\prime}$ which means that both incident and scattered light polarizations were parallel to either the $(z z)$ or $\left(x^{\prime} x^{\prime}\right)$ dimension of the substrate.

\section{Results and Discussion}

Raman spectra of our (110)-oriented pure PBCO and Fe, Co, $\mathrm{Ni}, \mathrm{Zn}, \mathrm{Ga}$, and $\mathrm{Al}$ doped $\mathrm{PBCO}$ thin films are shown in Figures 2-8 and Table 2 .

In the Raman spectrum of the (110)-oriented pure PBCO film, we observed four prominent Raman modes in $z z$ polarization: $\sim 130 \mathrm{~cm}^{-1}, \sim 150 \mathrm{~cm}^{-1}, \sim 440 \mathrm{~cm}^{-1}$, and $\sim 520 \mathrm{~cm}^{-1}$. These Raman modes are related to $\mathrm{Ba}, \mathrm{Cu}(2)$, inphase with $\mathrm{O}(2)-\mathrm{O}(3)$, and $\mathrm{O}$ (4) apical oxygen vibration along $c$-axis, respectively. Our observed Raman modes in $\mathrm{PBCO}$ are in complete agreement with [13-15].
We also observed four prominent $A_{g}$ lines in $\mathrm{zz}$ polarization Raman spectra of our (110)-oriented $\mathrm{Ga}, \mathrm{Al}, \mathrm{Fe}$, and Co doped thin films. Three of them were at $\sim 130 \mathrm{~cm}^{-1}$, $\sim 160 \mathrm{~cm}^{-1}$, and $\sim 440 \mathrm{~cm}^{-1}$, which belong to Raman vibrational modes of $\mathrm{Ba}, \mathrm{Cu}(2)$, and $\mathrm{O}(2)-\mathrm{O}$ (3) along $c$-axis, respectively. The fourth Raman mode related to the $\mathrm{O}$ (4) apical oxygen vibration mode was observed in the frequency regime $\left(485-502 \mathrm{~cm}^{-1}\right)$.

Next, we observed $B_{1 \mathrm{~g}}$-like Raman mode near $300 \mathrm{~cm}^{-1}$ in all of our thin film samples. This mode belongs to the "out-of-phase vibrations of the $\mathrm{O}(2)$ and $\mathrm{O}(3)$ atoms" in $c$ axis direction [4], and it is allowed only in $x x$ or $y y$ polarizations. Surprisingly, we observed this mode in $z z$-orientation in our samples. The observation of this $B_{1 \mathrm{~g}}$-like mode in the $z z$-polarization Raman spectrum of (110)-oriented PBCO thin film can tentatively be explained by either the presence of small islands with different (e.g., $c$-axis) orientation or a small misorientation of $<001>$ direction with respect to the substrate edges.

An additional Raman mode near $600 \mathrm{~cm}^{-1}$ was observed in the Raman spectra of our $\mathrm{Ga}, \mathrm{Al}, \mathrm{Fe}$, and Co doped PBCO thin film samples. However, we did not observe this Raman mode in the Raman spectra of pure $\mathrm{PBCO}$ and $\mathrm{Zn}$ or $\mathrm{Ni}$ doped PBCO thin film. We discuss these results in detail below.

\subsection{Behavior of Raman Mode Corresponding to Apical Oxygen} $O$ (4) Vibration. The Raman mode corresponding to the $\mathrm{O}$ (4) apical oxygen vibration was observed in the frequency regime $\left(485-502 \mathrm{~cm}^{-1}\right)$ of the Raman spectra on $\mathrm{Ga}, \mathrm{Al}, \mathrm{Fe}$, and Co doped PBCO thin films. This is the softening of the Raman mode $\sim 520 \mathrm{~cm}^{-1}$ corresponding to the vibration of the apical oxygen $\mathrm{O}(4)$ along $c$-axis in pure PBCO. This mode behaves in many ways similar to the axial stretching mode of the $\mathrm{O}(4)$ apical oxygen against the $\mathrm{Cu}(1)$ in YBCO $\left(\sim 500 \mathrm{~cm}^{-1}\right)$. Similar type of Raman mode for the apical oxygen vibration has been reported in [14, 15, 19-22]. On the contrary, we observed no shift in the Raman mode of apical oxygen in the Raman spectra of $\mathrm{Ni}$ and $\mathrm{Zn}$ doped PBCO samples, again in agreement with $\mathrm{Xu}$ [19]. Here, we discuss effect of substituting $\mathrm{Fe}, \mathrm{Co}, \mathrm{Ni}, \mathrm{Zn}, \mathrm{Ga}$, and $\mathrm{Al}$ with $\mathrm{Cu}$ ions in PBCO in the context of the behavior of this Raman mode.

Kakihana et al. [22] have discussed the role of $\mathrm{Cu}(1)-\mathrm{O}$ (4) and $\mathrm{Cu}(2)-\mathrm{O}$ (4) bond lengths for the vibrational frequency of apical oxygen on trivalent ions on $\mathrm{Al}, \mathrm{Fe}$, and $\mathrm{Co}$ doped YBCO, where the vibrational frequency $\omega$ of apical oxygen followed the relation,

$$
\omega^{2}=\frac{A}{r_{\mathrm{Cu}(1)-\mathrm{O}(4)}^{3}}+\frac{B}{r_{\mathrm{Cu}(2)-\mathrm{O}(4)}^{3}},
$$

and decreased with the substitution of them with $\mathrm{Cu}$ ion in YBCO. On the contrary, the Rietveld refinement of neutron diffraction data showed that all of these ions replaced $\mathrm{Cu}$ from $\mathrm{Cu}$ (1) ion location. The structural changes occurred in such a way that $\mathrm{Cu}(1)-\mathrm{O}$ (4) bond length decreased by 0.1 $\mathrm{A}^{0}$ per $\mathrm{Co}$ atom and $\mathrm{Cu}(2)-\mathrm{O}(4)$ bond length increased by $0.3 \mathrm{~A}^{0}$ per $\mathrm{Co}$ atom for $15 \% \mathrm{Cu}$ substitution. $\mathrm{Al}$ ion 

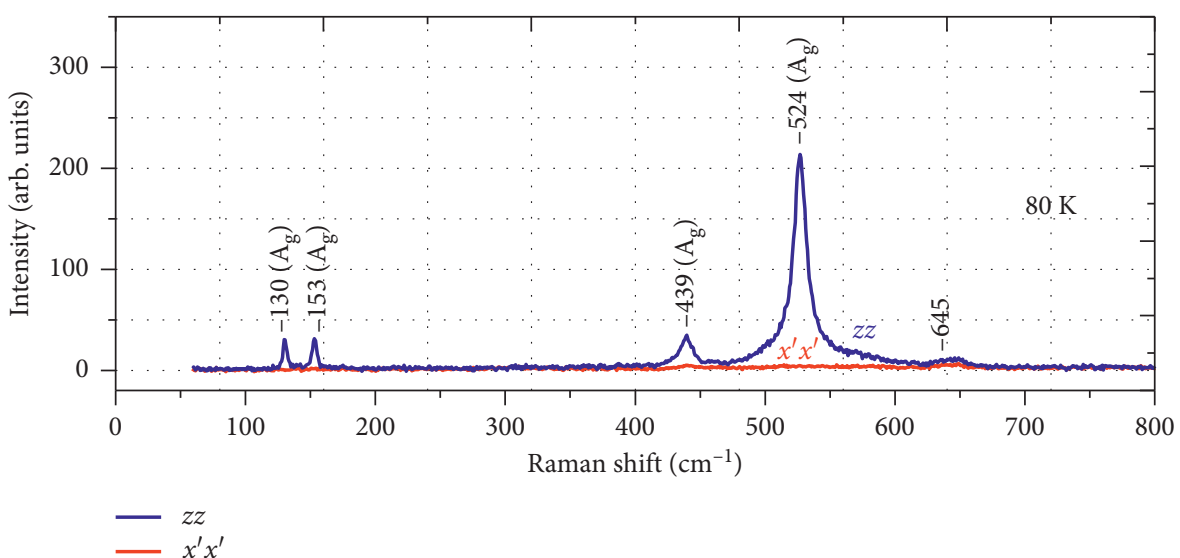

(a)
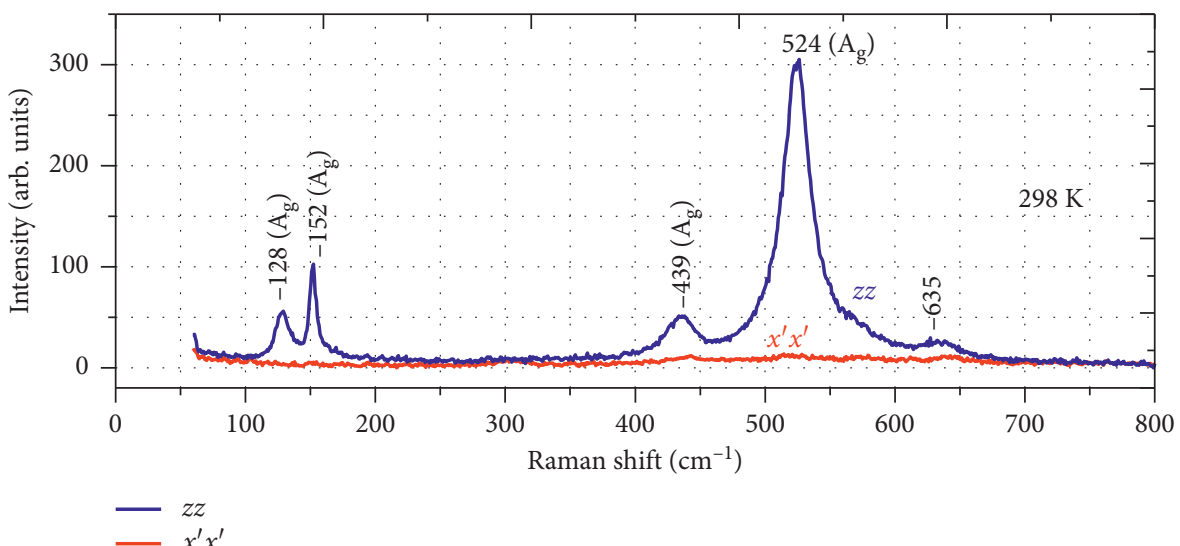

(b)

FIgURe 2: $z z$ and $x^{\prime} x^{\prime}$ polarization Raman spectra of (110)-oriented PBCO thin films.

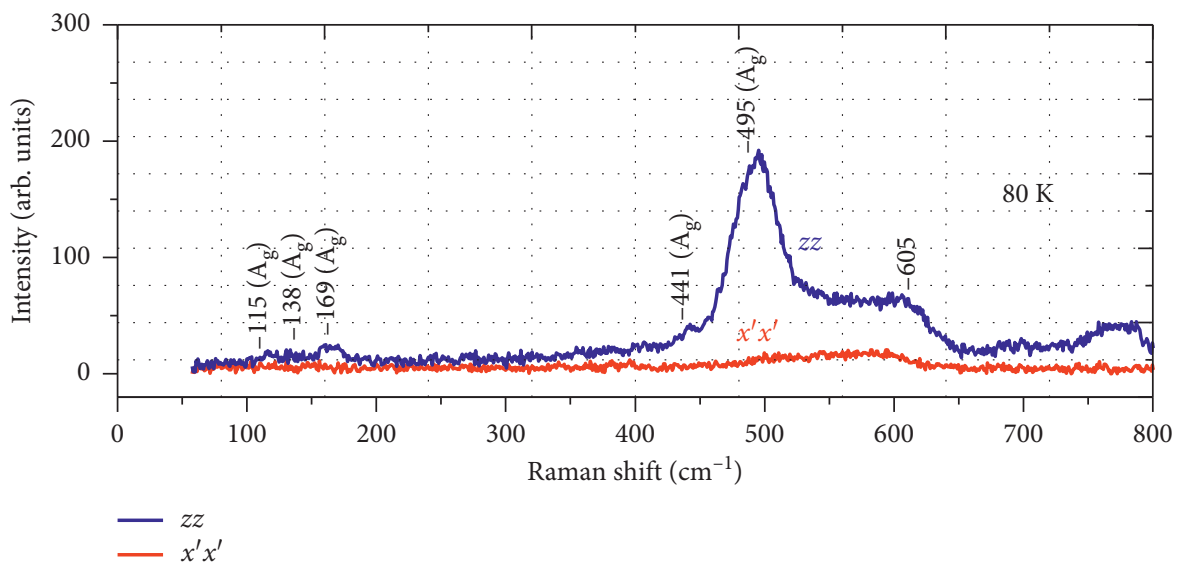

(a)

Figure 3: Continued. 


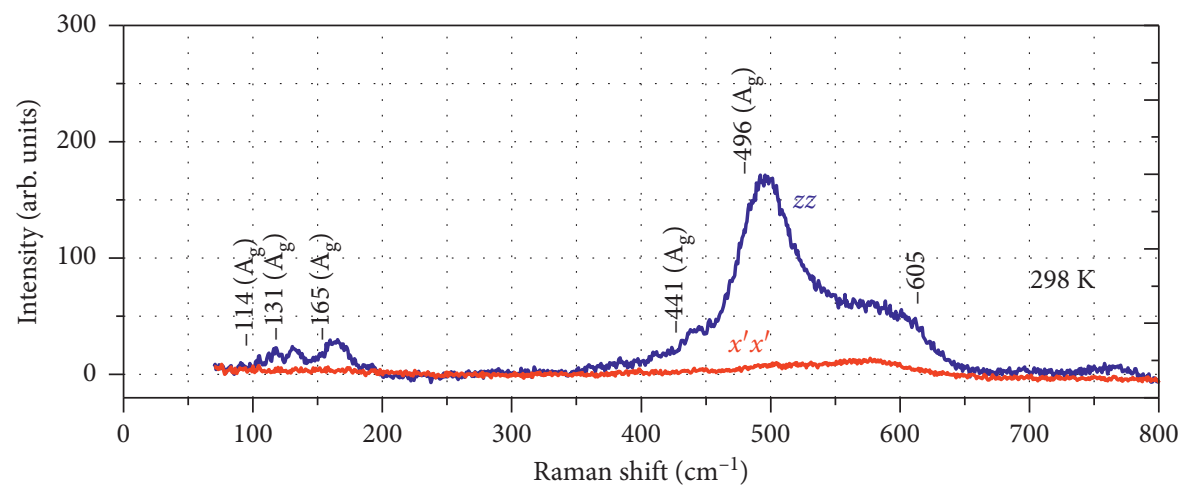

$-\begin{gathered}z z \\ -\quad x^{\prime} x^{\prime}\end{gathered}$

(b)

Figure 3: $z z$ and $x^{\prime} x^{\prime}$ polarization Raman spectra of (110)-oriented Al doped PBCO thin films.

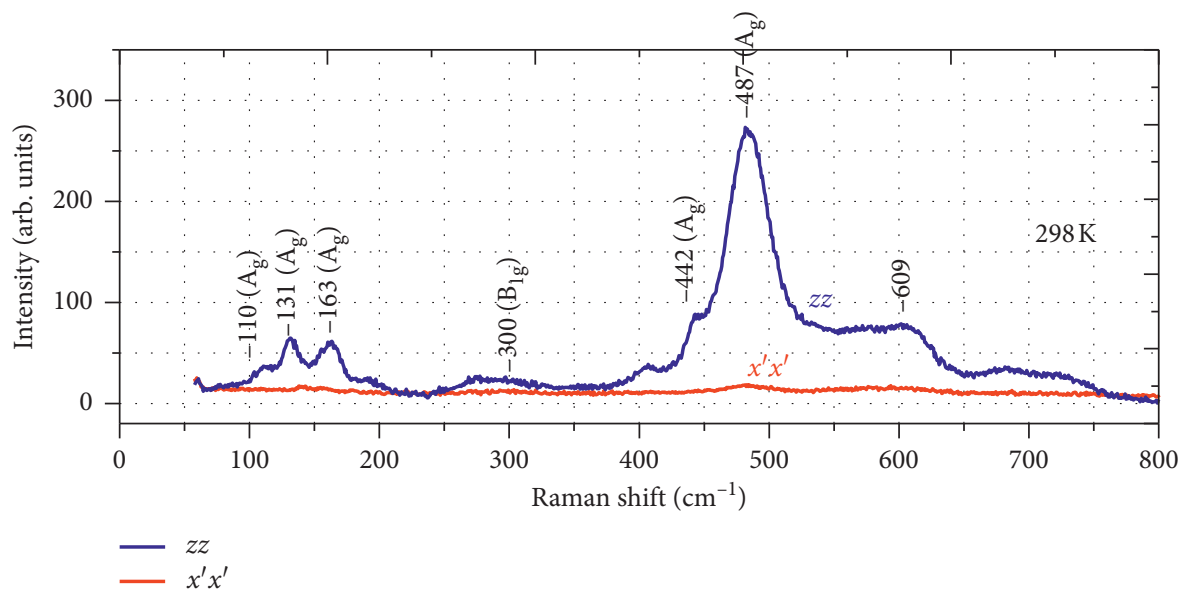

(a)

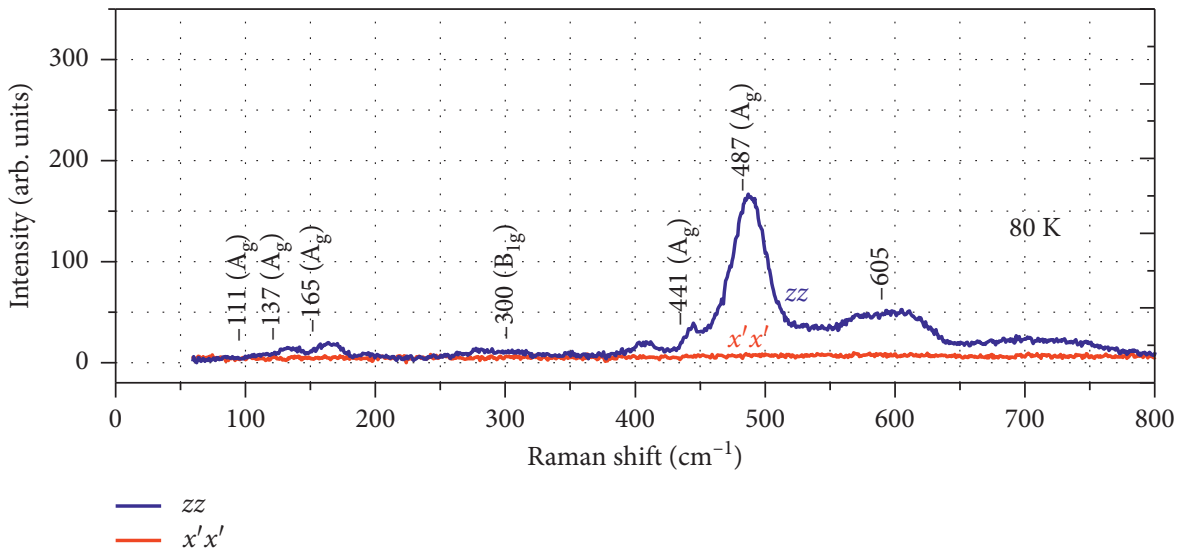

(b)

Figure 4: $z z$ and $x^{\prime} x^{\prime}$ polarization Raman spectra of (110)-oriented Ga doped PBCO thin film.

substitution in $\mathrm{PBCO}$ also behaved similarly but with a larger change in the bond lengths [23].

Using normal mode calculations, Roughani [10] and Bates et al. [11, 12] described the behavior of the apical oxygen vibrational mode based on the changes in the interatomic force constants and the bond lengths on trivalent and divalent metal doped YBCO. The substitution of $\mathrm{Cu}(1)$ by $\mathrm{Co}$ in $\mathrm{Cu}-\mathrm{O}$ chains decreased the $\mathrm{Cu}(1)-\mathrm{O}$ (4) bond 


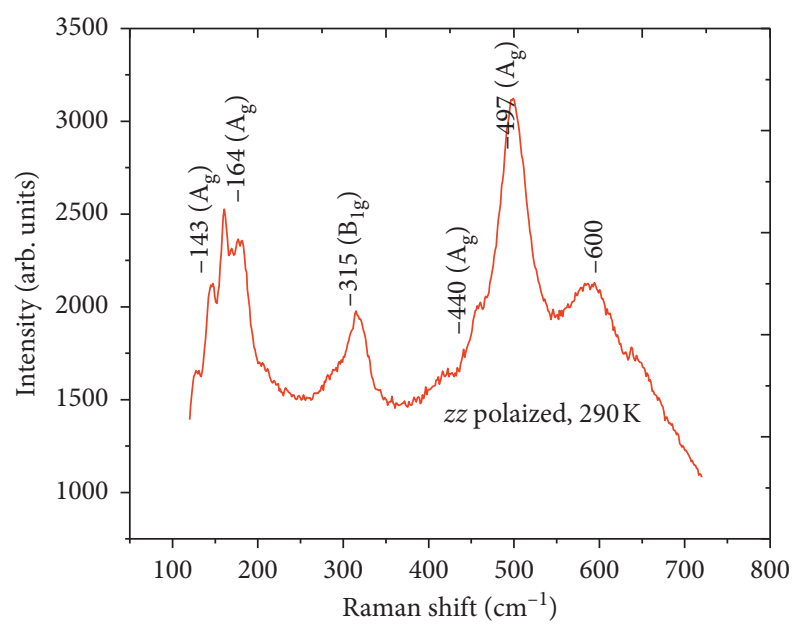

FIgURE 5: $z z$ polarization Raman spectrum of (110)-oriented Co doped PBCO thin film.

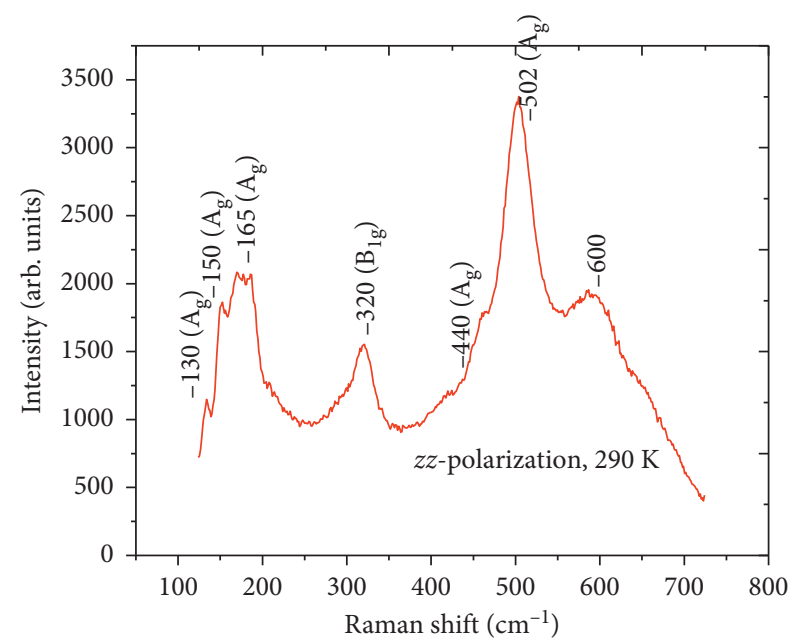

Figure 6: $z z$ polarization Raman spectrum of (110)-oriented Fe doped $\mathrm{PBCO}$ thin film.

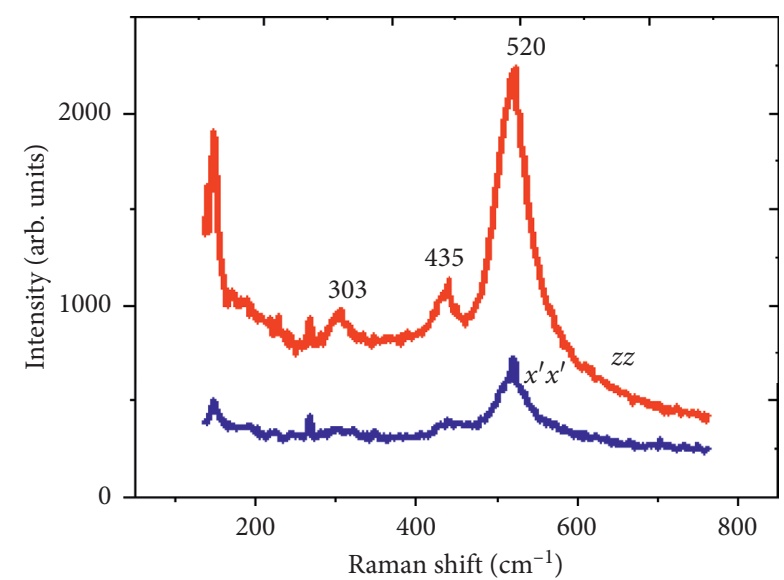

Figure 7: $z z$ and $x^{\prime} x^{\prime}$ polarized Raman spectra of (110)-oriented Zn doped PBCO thin film.

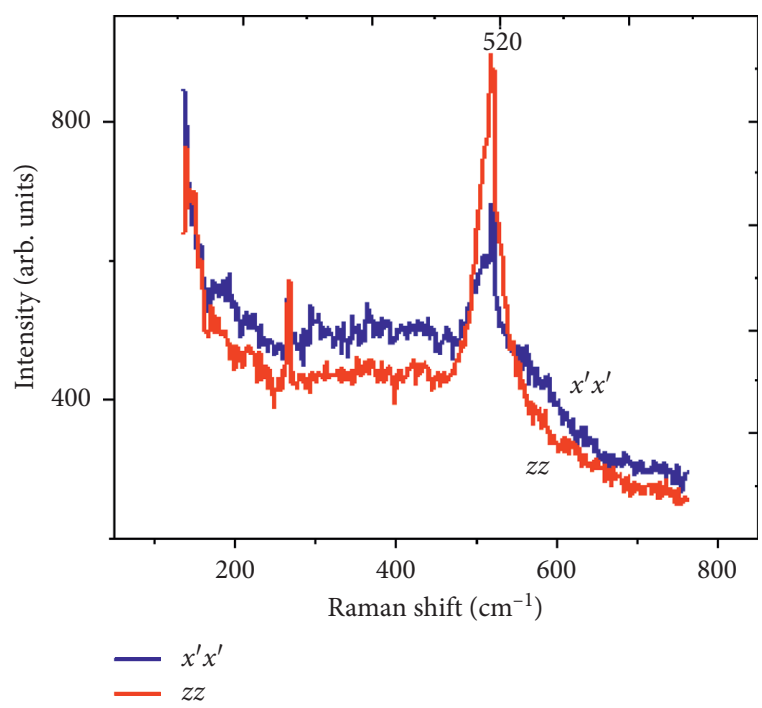

Figure 8: $z z$ and $x^{\prime} x^{\prime}$ polarization Raman spectra of (110)-oriented Ni doped PBCO thin film.

length but increased the $\mathrm{Cu}(2)-\mathrm{O}$ (4) bond length causing the softening of the apical oxygen-related Raman vibrational mode.

Based on the behavior of Raman mode corresponding to the apical oxygen vibration along the $c$-axis on YBCO and looking at the similarity in the lattice structure of $\mathrm{YBCO}$ and $\mathrm{PBCO}$, we argue that the trivalent atoms $\mathrm{Ga}, \mathrm{Al}, \mathrm{Fe}$, and $\mathrm{Co}$ substitute $\mathrm{Cu}$ ions from $\mathrm{Cu}(1)$ site and divalent atoms $\mathrm{Zn}$ and $\mathrm{Ni}$ substitute $\mathrm{Cu}$ from the $\mathrm{Cu}(2)$ site of PBCO lattice as well.

3.2. Behavior of Raman Mode at Cu-O Chain Site. The Raman mode near $600 \mathrm{~cm}^{-1}$ in the Raman spectra of $\mathrm{Al}, \mathrm{Ga}, \mathrm{Co}$, and Fe doped PBCO thin film represents the vibration of $\mathrm{O}(1)$ atom along the $\mathrm{Cu}-\mathrm{O}$ chain of the $\mathrm{PBCO}$ unit cell. This is a forbidden Raman mode in PBCO by group theory as $\mathrm{Cu}$ and $\mathrm{O}$ in the $\mathrm{Cu}-\mathrm{O}$ chains are at the inversion center of the $\mathrm{PBCO}$ unit cell. However, since the symmetry is broken in $\mathrm{Al}, \mathrm{Ga}$, $\mathrm{Co}$, and Fe doped PBCO due to the substitution of $\mathrm{Cu}$ (1) ions with these substituents; this mode has become Raman active.

It is noteworthy to mention the results from the other experiments including the Rietveld refinement on the neutron diffraction measurement of trivalent metal-doped YBCO [22], where these dopants created disorder in $\mathrm{Cu}-\mathrm{O}$ chain and $\mathrm{O}(1)$ was statistically distributed in a less symmetric position $(x, 1 / 2,0)$. In addition, the neutron diffraction performed by Zolliker et al. on Co doped YBCO showed similar disorder phenomenon in $\mathrm{Cu}-\mathrm{O}$ chains [24]. Comparing the similarity of the $\mathrm{Cu}-\mathrm{O}$ chains in both $\mathrm{YBCO}$ and $\mathrm{PBCO}$ and the appearance of Raman peak near $600 \mathrm{~cm}^{-1}$ in our $\mathrm{Al}, \mathrm{Ga}, \mathrm{Fe}$, and Co doped PBCO thin film samples, we argue that these metal ions substituted $\mathrm{Cu}(1)$ of $\mathrm{PBCO}$ lattice and destroyed the regular distribution of the oxygen 
TABle 2: Important Raman modes in (110)-oriented pure and Ga, Al, Fe, Co, Zn, and Ni doped PBCO thin films.

\begin{tabular}{lcccc}
\hline $\begin{array}{l}\text { Pure and metal doped } \\
\text { (110) PBCO thin films }\end{array}$ & $\begin{array}{c}\text { In-phase O (2)-O } \\
(3) B_{1 \mathrm{~g}} \text {-like mode }\end{array}$ & $\begin{array}{c}\text { In-phase O (2)-O (3) } \\
\text { vibration related } \mathrm{A}_{\mathrm{g}} \text { mode } \\
\left(\mathrm{cm}^{-1}\right)\end{array}$ & $\begin{array}{c}\text { Apical oxygen O (4) } \\
\text { vibration-related } \mathrm{A}_{\mathrm{g}} \text { mode } \\
\left(\mathrm{cm}^{-1}\right)\end{array}$ & $\begin{array}{c}\text { Disorder at Cu-O chain } \\
\text { site-related mode }\left(\mathrm{cm}^{-1}\right)\end{array}$ \\
\hline (110) PBCO & $\sim 300$ & $\sim 440$ & $\sim 524$ & Absent \\
(110) Ga doped PBCO & $\sim 300$ & $\sim 440$ & $\sim 485$ & $\sim 605$ \\
(110) Al doped PBCO & $\sim 300$ & $\sim 440$ & $\sim 495$ & $\sim 605$ \\
(110) Fe doped PBCO & $\sim 295$ & $\sim 440$ & $\sim 502$ & $\sim 600$ \\
(110) Co doped PBCO & $\sim 296$ & $\sim 440$ & $\sim 597$ & $\sim 600$ \\
(110) Zn doped PBCO & $\sim 303$ & $\sim 435$ & $\sim 520$ & Absent \\
(110) Ni doped PBCO & - & $\sim 430$ & & Absent \\
\hline
\end{tabular}

atoms in $\mathrm{Cu}-\mathrm{O}$ chain. This also induced a strong disorder in $\mathrm{Cu}-\mathrm{O}$ chains, possibly due to the formation of the metal clusters.

3.3. Behavior of Raman Mode Corresponding to In-Phase Vibrations of the $\mathrm{O}(2)$ and $\mathrm{O}$ (3) at $\mathrm{Cu}-\mathrm{O}_{2}$ Plane Site. We observed a much weaker $440 \mathrm{~cm}^{-1}$ Raman mode in our Raman spectra that belongs to the "in-phase vibrations of the $\mathrm{O}(2)$ and $\mathrm{O}(3)$ " atoms in the $\mathrm{Cu}-\mathrm{O}_{2}$ planes along the $c$-axis direction. The vibrational frequency of this Raman mode remained unaltered in trivalent $\mathrm{Fe}, \mathrm{Co}, \mathrm{Ga}$, and $\mathrm{Al}$ iondoped PBCO thin film but shifted down to $435-430 \mathrm{~cm}^{-1}$ on $\mathrm{Zn}$ and $\mathrm{Ni}$ doped PBCO thin films. The phonon vibration of the oxygen atoms in the $\mathrm{CuO}_{2}$ plane was influenced by the substitution of $\mathrm{Cu}(2)$ with $\mathrm{Zn}$ and $\mathrm{Ni}$, and therefore, we argue that $\mathrm{Zn}$ and $\mathrm{Ni}$ ion substituted $\mathrm{Cu}$ at the $\mathrm{Cu}$ (2) site of the PBCO lattice. On the contrary, as the vibrational frequency did not change with the $\mathrm{Fe}, \mathrm{Co}, \mathrm{Ga}$, and $\mathrm{Al}$ doping, we argue that they did not replace any $\mathrm{Cu}$ ion from $\mathrm{Cu}(2)$ site (the $\mathrm{CuO}_{2}$ planes).

\section{Conclusions}

We performed Raman scattering measurement on pure and $\mathrm{Al}, \mathrm{Ga}, \mathrm{Fe}, \mathrm{Co}, \mathrm{Zn}$, and Ni ion-doped (110)-oriented PBCO thin films and investigated the effects of different ion substitution for $\mathrm{Cu}(1)$ or $\mathrm{Cu}(2)$ in the lattice of PBCO.

The Raman spectra taken with $z z$ polarization on (110)oriented pure and $\mathrm{Ga}, \mathrm{Al}, \mathrm{Fe}$, and $\mathrm{Co} \mathrm{PBCO}$ films showed three prominent $A_{\mathrm{g}}$ peaks at $\sim 130 \mathrm{~cm}^{-1}, \sim 160 \mathrm{~cm}^{-1}$, and $\sim 440 \mathrm{~cm}^{-1}$ and an apical oxygen $\mathrm{O}$ (4) vibration-related Raman mode between 480 and $502 \mathrm{~cm}^{-1}$. However, this apical oxygen vibration-related Raman mode remained unaffected in the spectra of $\mathrm{Ni}$ or $\mathrm{Zn}$ doped $\mathrm{PBCO}$ thin films compared to the Raman spectrum of pure PBCO thin film. We explained these results in correlation with $\mathrm{Cu}(1)-\mathrm{O}$ (4) and $\mathrm{Cu}(2)-\mathrm{O}(4)$ bond lengths due to the substitution of $\mathrm{Cu}$ ions.

In addition, we observed a new Raman mode near $600 \mathrm{~cm}^{-1}$ in the Raman spectra of $\mathrm{Ga}, \mathrm{Al}, \mathrm{Fe}$, and Co doped PBCO thin films. This forbidden Raman mode became Raman active because of the broken symmetry at the $\mathrm{Cu}-\mathrm{O}$ chain site when these ions substituted $\mathrm{Cu}$ (1) partially. When a divalent $\mathrm{Cu}(1)$ was substituted by trivalent ions $\mathrm{Ga}, \mathrm{Al}, \mathrm{Fe}$, and $\mathrm{Co}$, the symmetry of the PBCO crystal was broken leading to this Raman mode. However, we did not observe this Raman mode in the Raman spectra of pure PBCO and $\mathrm{Zn}$ or Ni doped PBCO thin films indicating that $\mathrm{Zn}$ or Ni did not substitute $\mathrm{Cu}(1)$ at the $\mathrm{Cu}-\mathrm{O}$ chain site.

On the contrary, the Raman mode at $\sim 440 \mathrm{~cm}^{-1}$ corresponding to "O (2)-O (3) in-phase vibration" in $c$-axis direction at the $\mathrm{CuO}_{2}$ planes remained unaffected on $\mathrm{Fe}, \mathrm{Co}$, $\mathrm{Ga}$, and $\mathrm{Al}$ doped PBCO thin films. However, it softened to $430-435 \mathrm{~cm}^{-1}$ on $\mathrm{Zn}$ or $\mathrm{Ni}$ doped $\mathrm{PBCO}$ thin films as the vibration of the oxygen atoms at $\mathrm{Cu}-\mathrm{O}_{2}$ plane was influenced by the substitution of $\mathrm{Cu}(2)$ with $\mathrm{Zn}$ or $\mathrm{Ni}$ ions. Therefore, we argue that $\mathrm{Zn}$ and $\mathrm{Ni}$ ions substitute $\mathrm{Cu}(2)$ at $\mathrm{CuO}_{2}$ planes site but $\mathrm{Ga}, \mathrm{Al}, \mathrm{Fe}$, and $\mathrm{Co}$ ions do not.

Based on the analysis of the Raman modes corresponding to the phonon vibrations of "in-phase $\mathrm{O}(2)-\mathrm{O}$ (3)", $\mathrm{O}(4)$ apical oxygen, and $\mathrm{Cu}-\mathrm{O}$ chain along $b$-axis, we conclude that trivalent ions $\mathrm{Fe}, \mathrm{Co}, \mathrm{Ga}$, and $\mathrm{Al}$ replace $\mathrm{Cu}(1)$ in $\mathrm{Cu}-\mathrm{O}$ chains and divalent ions $\mathrm{Ni}$ and $\mathrm{Zn}$ replace $\mathrm{Cu}(2)$ in $\mathrm{CuO}_{2}$ planes of the PBCO lattice structure. These results are in complete agreement with the conclusions of our electrical transport studies on these samples $[16,17]$.

\section{Data Availability}

Data used in this study are available from the corresponding author upon request.

\section{Disclosure}

The views expressed herein are those of the authors and are not necessarily those of WiSys or UW System.

\section{Conflicts of Interest}

The authors declare that they have no conflicts of interest.

\section{Acknowledgments}

This work was supported in part by WiSys and UW System Applied Research Grant \#102-4-812000-AAH1775 (2019-2021).

\section{References}

[1] R. McCrery, Raman Spectroscopy for Chemical Analysis, vol. 157, Wiley Inter Science Publication, Hoboken, NJ, USA, 2000.

[2] M. Cardona and G. Guntherodt, Light Scattering in Solids I, Springer-Verlag, Berlin, Germany, 1991. 
[3] C. Thomson and G. Kaczmarczyk, Vibrational Raman Spectroscopy of High-Temperature Superconductors, J. M. Chalmers and P. R. Griffiths, Eds., pp. 2651-2669, John Wiley \& Sons, Chichester, UK, 2002.

[4] M. Cardona, "Raman scattering in high Tc superconductors: phonons, electrons, and electron-phonon interaction," Physica C: Superconductivity, vol. 317-318, pp. 30-54, 1999.

[5] K. F. McCarty, J. Z. Liu, R. N. Shelton, and H. B. Radousky, "Raman-active phonons of a twin-free $\mathrm{Ba}_{2} \mathrm{Cu}_{3} \mathrm{O}_{7}$ crystal: a complete polarization analysis," Physical Review B, vol. 41, no. 13 , pp. $8792-8797,1990$.

[6] A. Pinczuck and E. Burstein, Fundamentals in Inelastic Scattering in Semiconductors and Insulators, M. Cardona and G. Guntherodt, Eds., Springer-Verlag, Berlin, Germany, 1984.

[7] R. J. Hemley and H. K. Mao, "Single-crystal micro-raman spectroscopy of phases in the $\mathrm{Y}-\mathrm{Ba}-\mathrm{Cu}-\mathrm{O}$ superconductor," Physical Review Letters, vol. 58, no. 22, pp. 2340-2342, 1987.

[8] C. Thomson, M. Cardona, B. Gegenheimer, and R. Liu, "Raman scattering in single crystals of YBa2Cu3O7- $\delta$," Physica C, vol. 153-155, pp. 262-263, 1988.

[9] M. Kakihana, S.-G. Eriksson, L. Börjesson, L.-G. Johansson, C. Ström, and M. Käll, "Charge-transfer and compression effects of isomorphous substitutions in $\mathrm{YBa}_{2} \mathrm{Cu}_{3} \mathrm{O}_{7}$," Physical Review B, vol. 47, no. 9, pp. 5359-5366, 1993.

[10] B. Roughani, L. C. Sengupta, J. L. Aubel, S. Sundaram, and W. C. H. Joiner, "Raman spectra of $\mathrm{YBa} 2(\mathrm{Cu} 1-\mathrm{xMx}) 3 \mathrm{O} 7-\delta$ with transition metal dopants of $\mathrm{Fe}, \mathrm{Co}$, and Zn," Physica $C$, vol. 171, pp. 77-86, 1990.

[11] F. E. Bates, "Normal modes of tetragonal $\mathrm{YBa}_{2} \mathrm{Cu}_{3} \mathrm{O}_{6}$ and orthorhombic $\mathrm{YBa}_{2} \mathrm{Cu}_{3} \mathrm{O}_{7}$," Physical Review B, vol. 39, no. 1, pp. 322-327, 1989.

[12] F. E. Bates and J. E. Eldridge, "Normal-coordinate calculation of the zero-wavevector vibrations of $\mathrm{YBa}_{2} \mathrm{Cu}_{3} \mathrm{O}_{7}$," Solid State Communications, vol. 64, no. 12, pp. 1435-1439, 1987.

[13] I.-S. Yang, G. Burns, F. H. Dacoul, and C. C. Suei, "Polarized raman measurements of $\mathrm{Y}_{1-\mathrm{x}} \mathrm{Pr}_{\mathrm{x}} \mathrm{Ba}_{2} \mathrm{Cu}_{3} \mathrm{O}_{7}$," Physical Review $B$, vol. 42, pp. 4240-4243, 1990.

[14] M. Iliev, C. Thomsen, V. Hadjiev, and M. Cardona, "Resonant Raman scattering of oxygen-deficient $\mathrm{YBa} 2 \mathrm{Cu} 3 \mathrm{O} 7-\delta$ : evidence for the coexistence of ortho-I, ortho-II, and tetragonal microstructures," Physical Review B, vol. 47, no. 18, pp. 12341-12344, 1993.

[15] H. B. Radousky, K. F. McCarty, J. L. Peng, and R. N. Shelton, "Preparation and Raman analysis of single-phase $\mathrm{Y}_{1-\mathrm{x}} \mathrm{Pr}_{\mathrm{x}} \mathrm{Ba}_{2} \mathrm{Cu}_{3} \mathrm{O}_{7-\delta}$, ” Physical Review B, vol. 39, no. 16, pp. 12383-12386, 1989.

[16] H. Kandel, T. P. Chen, and Z. Li, "Effect of Fe doping on electronic transport and raman scattering properties of (110) $\mathrm{PrBa}_{2} \mathrm{Cu}_{3} \mathrm{O}_{7}$ thin film," Materials Research Express, vol. 5, no. 2, Article ID 026417, 2018.

[17] H. Kandel, T.-P. Chen, S. Bourdo et al., "Electrical transport properties of (110)-oriented $\mathrm{PrBa}_{2}\left(\mathrm{Cu}_{0.8} \mathrm{Ga}_{0.2}\right)_{3} \mathrm{O}_{7}$ thin films," Applied Physics Letters, vol. 100, no. 25, Article ID 252601, 2012.

[18] D. L. Roussseau, R. P. Bauman, and S. P. S. Porto, "The polarized raman spectra of $\mathrm{CsCdCl}_{3}$ single crystals," Journal of Raman Spectroscopy, vol. 10, no. 4, pp. 264-265, 1981.

[19] Y. Xu, S. S. Ata-Allah, M. G. Berger, and O. Glück, "RareEarth ion size effect on resistivity, susceptibility, and superconductivity of RBa2Cu3-xZnxO7-y $(\mathrm{R}=\mathrm{Yb}, \mathrm{Er}, \mathrm{Y}, \mathrm{Dy}, \mathrm{Gd}$, $\mathrm{Eu}, \mathrm{Sm}$, and $\mathrm{Nd}$ )," Physical Review B, vol. 53, no. 22, pp. 15245-15253, 1996.
[20] A. Erle and G. Guntherodt, "Influence of cobalt substitution on the Raman spectrum of $\mathrm{YBa} 2 \mathrm{Cu} 3 \mathrm{O} 7-\delta$," Physica C: Superconductivity, vol. 171, no. 3-4, pp. 216-222, 1990.

[21] E. Sodtke, C. Andrzejak, D. Guggi, and Y. Xu, "Preparation of a-axis oriented $\mathrm{YBa}_{2} \mathrm{Cu}_{3} \mathrm{O}_{7}$ and $\mathrm{PrBa}_{2} \mathrm{Cu}_{3-\mathrm{x}} \mathrm{Ga}_{\mathrm{x}} \mathrm{O}_{7}$ thin films," Physica C: Superconductivity, vol. 180, no. 1-4, pp. 50-53, 1991.

[22] M. Kakihana, L. Börjesson, S. Eriksson, P. Svedlindh, and P. Norling, "Raman spectra, superconductivity, and structure of Co-substituted $\mathrm{YBa}_{2} \mathrm{Cu}_{3} \mathrm{O}_{7-\delta}$," Physical Review B, vol. 40, no. 10 , pp. 6787-6796, 1989.

[23] S. Uma, T. Sarkar, K. Sethupathi et al., "Structural, magnetic, and crystalline electric-field effects in single crystals of $\mathrm{Y}_{1-\mathrm{x}} \mathrm{Pr}_{\mathrm{x}} \mathrm{Ba}_{2} \mathrm{Cu}_{3} \mathrm{O}_{7-\delta}$, "Physical Review B, vol. 53, no. 10, pp. 6829-6835, 1996.

[24] P. Zooliker, D. E. Cox, J. M. Tranquada, and G. Shirane, "Neutron-powder-diffraction study of nuclear and magnetic structure in $\mathrm{YBa}_{2} \mathrm{Cu}_{3-\mathrm{x}} \mathrm{Co}_{\mathrm{x}} \mathrm{O}_{7+\mathrm{y}}$ with $x=0.84$ and $y=0.32$," Physical Review B, vol. 38, pp. 6575-6582, 1988. 